\title{
Health Informatics Association for Latin-America and Caribbean (IMIA-LAC)
}

\author{
Marcelo Lúcio da Silva ${ }^{1,2}$, Luis Gustavo Gasparini Kiatake², Emma Alejandra Chávez Mora3 ${ }^{3}$, \\ Cynthia Villalba ${ }^{4}$, Lady Murrugarra ${ }^{5}$, Paula Daniela Otero ${ }^{6}$ \\ 1 Health Informatics Association for Latin-America and Caribbean (IMIA-LAC) \\ 2 Brazilian Health Informatics Association (SBIS) \\ 3 Chilean Health Informatics Society (ACHISA) \\ ${ }^{4}$ Paraguayan Society of Health Informatics (SPIS) \\ 5 Peruvian Biomedical Informatics Association (APIB) \\ 6 Department of Health Informatics at Hospital Italiano de Buenos Aires, Argentina
}

\section{Overview}

Since 2018, the Health Informatics Association for Latin-America and Caribbean (IMIA-LAC) has been restructuring to strengthen its sustainability and representativeness in its region.

Some of the goals aimed at this restructuring are:

- to revise the statute of the entity, making it more appropriate to the demands of the region and aligned with the present;

- to implement the documentation of its internal processes, aiming the continuity of actions to each new term of office;

- to encourage the establishment of national associations in all countries of the region;

- to improve the federation membership process;

- to enable the membership of academic and corporate entities, as in IMIA;

- to increase the exchange of knowledge and experience among the countries of the region;

- to encourage the implementation of national eHealth policies in the region;

- to pursue closer ties with PAHO and WHO to foster digital health throughout the region, especially in the least developed countries;

- to set the realization of Infolac - the Latin American Congress on Health Informatics - regularly every two years, interspersed with Medinfo.
The current IMIA-LAC members are:

- Argentine Association of Medical Informatics (AAIM)

- Brazilian Health Informatics Association (SBIS)

- Chilean Health Informatics Society (ACHISA)

- Cuban Medical Informatics Society (SOCIM)

- Mexican Medical Informatics Association (AMIM)

- Peruvian Biomedical Informatics Association (APIB)

- Venezuelan Association of Computer Science in Health (AVIS)

In addition, activities were reported by the Paraguayan Society of Health Informatics (SPIS) and the Department of Health Informatics at Hospital Italiano de Buenos Aires (Argentina).

\section{Member Reports}

\subsection{Brazilian Health Informatics Association (SBIS)}

Founded in 1986, SBIS (www.sbis.org.br) aims to contribute to the improvement and transformation of health through the appropriate use of Information and Communication Technologies.

Proceeding with excellence, impartiality, diversity, ethics, commitment and enthusi- asm, SBIS has currently over 1600 members. Some SBIS achievements in the last year: - eSAÚDE \& PEP 2019 (eHealth \& EHR Conference)

SBIS held from December 02 to 04, 2019 the eHealth \& EHR Conference ("eSAÚDE \& PEP 2019“) in São Paulo. The event was attended by over 200 people and 50 speakers.

The conference has three main themes, one per day:

- Dec 02: Digital Certification

- Dec 03: The role of health professionals in the digital transformation

- Dec 04: The Brazilian Personal Data Protection Act ("LGPD") applied to healthcare

\section{- Software Certification}

The Electronic Health Record System (EHR-S) Certification Program was started in 2002, and in 2009 began certifying software by an audit to verify compliance with a broad set of information security, structure, content and functionality requirements. By January 2020, 70 systems have obtained SBIS certification.

- Professional Certification (cpTICS)

The SBIS Professional Certification Program was started in 2012 aiming to recognize the core competencies of health informatics professionals through the award of a Professional Certificate in 
Health Information and Communication Technology (cpTICS). By January 2020, 48 professionals were approved and received cpTICS certification.

- Journal of Health Informatics (JHI)

JHI, the SBIS's electronic science journal (http://www.jhi-sbis.saude.ws/), had its first issue released in October 2009. It is a free and open access peer-reviewed journal which offers an international means of disseminating original research results and interpretative reviews concerning the field of health informatics. By January 2020, 284 articles were published on 49 editions (11 volumes) of JHI.

\subsection{Chilean Health Informatics Society (ACHISA)}

In April 2019 a new Directory was elected by ACHISA members. The main aim of the new directory has been to order groups of interests and have a portfolio of member capabilities in the area of Health Informatics.

During 2019, collaborative initiatives in health informatics were developed in the national sphere such as raising challenges of Innovation in Health in EXPOMED in the Biobio region of Southern Chile, taking part of a panel in the Chilean Congress of Medical Students and at The International Congress of Telemedicine, Tele Health and Digital Health. ACHISA during the year worked closely to the group that has been preparing the Chilean Chapter of HL7.

The Association sponsored several initiatives such as the Digital Health Strategy Seminar for Chile - October 2019 - Santiago, Chile, The XIV University Conference on Health Information Systems - November 2019 - Buenos Aires, Argentina, and The International Congress of Telemedicine, Telehealth and Digital Health - December 2019 - Concepción, Chile.

In the national context we highlight the implementation of the Digital Hospital providing telemedicine services to the public system, the implementation of DART in 127 Ophthalmological Primary Care Units, and the development of the Centers for Health Piloting (CePis), which will have the mission of creating controlled environments for the creation and development of prototypes, clinical and technological validations of technology-based projects that improve health through a new Digital Attention Model (MAD).

\subsection{Paraguayan Society of Health Informatics (SPIS)}

SPIS was created in 2018 and joined more than 60 members by now.

During 2019 SPIS have concentrated in establishing working groups. For this purpose, the following working groups were created:

- Interoperability in health information systems

- Health informatics policy and laws

- Training courses

- Awareness, diffusion and events

The main activities of these groups were: get to know the importance of health informatics in Paraguay; participate, support and spread national and international of health informatics events and courses; and promote strategic alliance with international organizations.

\subsection{Peruvian Biomedical Informatics Association (APIB)}

\section{- First FAB Women Meeting}

The feminine power of all Latin America gathered in Lima, Peru, on October 23, 2019 to show how the use of Digital Manufacturing technologies has revolutionized their lives.

- International ICT Health Congress

Topics:

- Management by health processes

- Leadership in digital transformation

- Integrated health technology management systems

- International Congress of Scientific Research

About 30 experts and senior officials participated in the "Peru: Multi-Stakeholder Forum", in order to deliberate on the report "The era of digital interdepen- dence", prepared by the High Level Panel on Digital Cooperation of the Secretary General of the United Nations Organization (UN), Antonio Guterres.

\subsection{Department of Health Informatics at Hospital Italiano de Buenos Aires (Argentina)}

The Department of Health Informatics DHI (https://www.hospitalitaliano.org.ar/ infomed) was created in 2001, the Department performs functions such as health data management and technical management of computer systems. It is composed of different areas responsible for carrying out hospital information management: Clinical Informatics, Software Engineering, Business Intelligence and Biostatistics, Norms and procedures, IT infrastructure, Research and Technological Innovation, Implementation, Community health informatics, and Training and Quality in Information Systems, each with different responsibilities and with a team of nearly 200 professionals.

The Department of Health Informatics of the Hospital Italiano de Buenos Aires has developed over the last 20 years a deep redesign of its service provision network with the aim of achieving harmony between providing high quality of care, while managing costs and the ability to meet the needs of the population.

Activities in 2019:

- WHO - Collaboration Centre

The DHI has been working as World Health Organization Collaborating Centre in Knowledge Management since 2014, with the purpose to provide support in Digital Literacy Programs and to provide training on health information systems and electronic health records. Also to support the implementation of the eHealth Strategy among countries of the Americas and to support in the development, adoption and use of standards for health data information exchange between and within countries.

There was an active participation with PAHO and member states in different projects: 
- Introductory Course to Health Information Systems for the training of 100 leaders in Health Informatics in Argentina (16 weeks) The course was aimed at professionals working in health organizations with the need to train in leadership roles for the design and execution of health technology projects belonging to 20 provinces of Argentina

- Course on Principles of Interoperability and Health Standards for the training of 60 professionals from Ecuador (16 weeks). The online course was aimed at professionals from Ecuador who worked in health organizations with the need to understand the importance of interoperability in the field of health information systems.

- We continue working with BIREME on the development of a proof-ofconcept for the implementation of the standard Infobutton protocol, maintained by HL7, which connects with the VHL information sources so as to provide through Interoperability evidence based information in electronic health record systems The pilot started with the technical feasibility test, afterwards a content and performance validation was made. The next step is the implementation in Hospital Italiano's EHR. The experience will be presented at the annual conference organized by the Department

- Collaborated with the design of the IS4H framework and toolkit that was approved as Plan of Action for Strengthening Information Systems for Health 2019-2023 at the 57Th Directing Council 71St Session of the Regional Committee of WHO for the Americas. The goal of this plan of action is to strengthen the activities of Member States aimed at upgrading health systems through the use of interconnected and interoperable information systems. It will also help the Member States introduce information and communication technologies and improve information exchange and the management of structured and unstructured data for the benefit of public health.
- In the IX RELACSIS (Latin American and the Caribbean Network for Strengthening Health Information Systems) meeting held in Buenos Aires on August 2019 we participated as facilitators in the Group Work with all the attendees so as to analyze the strategic lines, objectives and indicators of the Plan of Action of IS4H, and generate recommendations on the actions that must be carried out in order to achieve them.

- MSc in Health Informatics

Our 2-year Master's Degree program in Health Informatics is aimed at professionals interested in knowing the complexity of this disciplinary field from different perspectives, and in developing the necessary skills to address the different challenges of health information systems.

It was launched in 2017 and has nearly 300 students that are mostly from Argentina but we also have students from countries such as Uruguay, Colombia, Chile, Mexico, Panama, Paraguay, Ecuador and Bolivia.

Our main objective is that our graduates are trained to assume positions that require a deep knowledge of information technologies and health organizations, endowed with creative thinking, capable of solving problems and generating new knowledge in multidisciplinary work teams.

Among the different courses that the students have the aim is that they can develop the necessary skills to apply the principles of Computer Science, Communication and Information to the organization, analysis, management and use of information in the health system.

\section{- Terminology Web Services}

The Department has been working on terminology services for more than 15 years as part of this initiative was created. E-Drugs is a system that guarantees the effectiveness of the drug prescription process for patients. It has both human knowledge and those that enable us with current technologies, embodied in a system that will benefit both health professionals, patients and healthcare organizations.
The system facilitates rapid access to secure, hierarchically and visually organized information in a way that facilitates the processing thereof; analysis and classifications, taking into account the risk of the interactions of different types of drugs, generating and collecting data for monitoring.

\section{- Health Informatics Glossary}

Health Informatics as a discipline has evolved by strengthening the interaction between professionals that belong to different areas such as Computer Science, Communication, Information, and its application in Biomedicine and Health. This integration highlighted the differences in knowledge between different professionals and the need to start a common vocabulary for health informatics projects.

Therefore, it was decided to prepare a Spanish glossary of Health Informatics, based on a evaluation of terms related to the discipline defined by specialists in the field. It consists of relevant terms that help in the understanding of Health Informatics, which must be detailed for a proper understanding, allowing the discipline to grow and deepen their knowledge. We consider it of great importance that all professionals working in the field of Health Informatics are familiar with the specific vocabulary and can deepen their definitions.

To facilitate access to the glossary, a web query and navigation tool was developed. The Web Glossary allows the retrieval of the terms quickly and efficiently. In addition, it will be possible to know the bibliographic citations that were used for the generation of the definitions, as well as synonyms and domains of the discipline to which the term is related.

The Health Informatics Glossary is a constantly growing project that will feed on the progress of the discipline and the generation of new content. Also, it has a comments section to add new terms and definitions.

- XIV University Conference on Health Information Systems

In November 2019, the 14th edition of the annual conference organized by DHI 
took place in Buenos Aires. This annual conference has the main objective of being the "meeting place" of those working on Health Information Systems in Argentina and the Latin American region where they can share their experiences and learn on all the advances that have been made on the field.

The meeting had over 4000 registrants.

Within the conference we also organized the first Nursing Informatics Symposium that had over 1800 registrants.

As international speakers were invited:

- Eric Poon - Duke University

- Heimar de Fatima Marin - Hospital Sírio Libanês, Brasil

- Aaron Noll - Data Scientist Sr, United States

- Hyeoun Ae Park - National University of Seoul, Korea

- James Agnew - Canada

- Jeffrey Wall - United States

- Kyung Hwan Kim - Korea

- Xavier Pastor Durán - Spain
- E-books

During 2019 we continue with the publication of Spanish e-books on different topics related to Health Information Systems. With think that these e-books can be used as guidance in Spanish for those working on the field in the Latin-American region where there is a lack of information in the language.

All these books are available through Amazon:

- Ethics, security and legislation of Health Information Systems

- Databases and Business Intelligence in Health

- Community Health Informatics

- Translational Computing

- Computer-Assisted Surgery

- Infrastructure of Health Information Systems

- Support Systems for Decision Making

- The complexity of medical thinking and decision making

- Information Systems for Health Management
- Evaluating Health Information Systems

- Principles of Interoperability in Health and Standards

- Software construction

- GPS: Project Management in Health

- Information Systems for Health

- Gestating Software in Health

- ReSIStiendo: Change management in health information systems

- ABC of PubMed

- Anesthesia Computer science applied to the specialty

- Computer Nursing applied to healthcare processes

- Interoperability in health and standards

- Contingency Design and instrumentation in Health Information Systems

- Glossary for Health Informatics

- Selection of our publications in Clinical Terminologies

- Selection of our publications in Electronic Prescription

- Selection of our publications in Computer Assisted Surgery

- Selection of our publications in Interoperability in Health and Standards. 